\title{
Clonal X-chromosome inactivation suggests that splenic cord capillary hemangioma is a true neoplasm and not a subtype of splenic hamartoma
}

\author{
A Chiu ${ }^{1, *}$, M Czader ${ }^{2}$ L Cheng $^{2}, \mathrm{RP}$ Hasserjian $^{3}, \mathrm{M}$ Wang $^{2}, \mathrm{~S}_{\text {Bhagavathi }}{ }^{2}$, \\ EM Hyjek $^{4}$, H Al-Ahmadie ${ }^{4}$, DM Knowles ${ }^{1}$ and A Orazi ${ }^{1}$ \\ ${ }^{1}$ Department of Pathology and Laboratory Medicine, Weill Cornell Medical College, New York, NY, USA; \\ ${ }^{2}$ Department of Pathology and Laboratory Medicine, Indiana University School of Medicine, Indianapolis, \\ IN, USA; ${ }^{3}$ Department of Pathology, Massachusetts General Hospital, Boston, MA, USA and ${ }^{4}$ Department of \\ Pathology, University of Chicago, Chicago, IL, USA
}

\begin{abstract}
Splenic hamartoma is a rare tumor-like lesion composed of structurally disorganized red pulp elements. It has been hypothesized that two other splenic lesions, cord capillary hemangioma and myoid angioendothelioma, may fall within the spectrum of splenic hamartoma, simply representing morphological variants. In this study, we compared the vascular and stromal composition of cord capillary hemangioma and myoid angioendothelioma with those of classical hamartoma. In addition, we assessed the clonal vs polyclonal nature of the lesions in nine female cases by performing clonality analysis for X-chromosome inactivation at the human androgen receptor locus (HUMARA) on laser-assisted microdissected samples. In 15 of 17 cases, increased reticulin and/or collagen content was observed. The classical hamartoma cases showed a vasculature predominantly composed of CD8 + CD31 + CD34 - splenic sinuses, whereas cases of cord capillary hemangioma and myoid angioendothelioma contained many CD8 - CD31 + CD34 + cord capillaries, but very little CD8 + vasculature. All cases lacked expression of D2-40 and Epstein Barr virus-encoded RNA. All cases showed a proliferation index of $\leq 5 \%$ by $\mathrm{Ki}-67$. Cases of classical hamartoma lacked significant perisinusoidal expression of collagen IV and low-affinity nerve growth factor receptor. Both markers were variably expressed in the other lesions. Increased CD163-positive histiocytes were found in four cases (three cord capillary hemangiomas and one myoid angioendothelioma). HUMARA analysis was informative in all nine tested cases, of which three cases showed a non-random X-chromosome inactivation pattern, indicating clonality. All three clonal cases were cord capillary hemangiomas. Our study has shown that in spite of considerable morphologic heterogeneity and overlapping features, classical hamartoma and cord capillary hemangioma and myoid angioendothelioma are different in terms of their vascular and stromal composition. Clonality analysis supports a true neoplastic origin for the cord capillary hemangioma. A larger study using additional immunohistochemical and molecular studies is necessary to further evaluate the biological significance of the current findings.
\end{abstract}

Modern Pathology (2011) 24, 108-116; doi:10.1038/modpathol.2010.168; published online 17 September 2010

Keywords: clonality; cord capillary hemangioma; hamartoma; myoid angioendothelioma; sclerosing angiomatoid nodular transformation; spleen

\footnotetext{
Correspondence: Dr A Orazi, MD, Department of Pathology and Laboratory Medicine, Weill Cornell Medical College, 525 East 68th Street, Room ST-707, New York, NY 10065, USA. E-mail: ato9002@med.cornell.edu

${ }^{*}$ Current address: Department of Pathology, Brigham and Women's Hospital, Boston, MA, USA.

Received 18 January 2010; revised 20 July 2010; accepted 28 July 2010; published online 17 September 2010
}

Splenic hamartoma is a tumor-like proliferation with ill-defined borders composed of structurally disorganized mature red pulp elements, and lacking organized lymphoid tissue (ie well-formed white pulp structures). Splenic hamartoma is a rare lesion, its incidence ranging from 0.17 to $0.2 \%$. It usually represents an incidental finding detected at autopsy or splenectomy. ${ }^{1,2}$ Splenic hamartoma has no gender 
predilection, and has been diagnosed at all ages (11 months to 86 years). ${ }^{2-4}$

The majority of patients with splenic hamartoma are asymptomatic. The $15 \%$ or so symptomatic patients present with abdominal discomfort, malaise, fever, splenomegaly, cytopenias, and rarely portal hypertension or rupture. ${ }^{5-12}$ Signs and symptoms are usually associated with large mass and female gender. ${ }^{13,14}$ Children with splenic hamartoma are more likely to be symptomatic than adults. ${ }^{15}$

The origin of splenic hamartoma is controversial. Some consider splenic hamartoma to be the result of focal developmental disturbance/congenital anomaly, malformation, or trauma. ${ }^{8,9}$ An association between splenic hamartoma and neoplastic hematologic diseases has also been suggested..$^{2,11,16}$

Splenic hamartoma exhibits considerable morphologic variation, and at times may be difficult to differentiate from other benign lesions of the spleen, benign vascular tumors in particular. On the basis of the concept that splenic hamartoma represents a proliferation of red pulp elements abnormally assembled into a pseudotumoral lesion, Krishnan and Frizzera ${ }^{17}$ proposed a classification scheme for splenic hamartoma based on the relative proportion of the various red pulp elements (eg cordal histiocytes, vessels, myoid cells) observed in a given case. Using this approach, the authors identified a classical hamartoma and three variant forms-including two other previously described entities, cord capillary hemangioma ${ }^{18}$ and myoid angioendothelioma ${ }^{19,20}$ —as well as the rare 'histiocyte-rich' variant. In its classical form, splenic hamartoma was defined as a relatively uniform lesion characterized by irregularly shaped vascular channels lined by CD8 + CD31 + CD34- endothelial cells (similar to splenic sinuses), surrounded by red pulp cords. In contrast to classical splenic hamartoma, cord capillary hemangioma was described as an angiomatoid proliferation displaying a strikingly lobular pattern and distinct lobular borders, in which the lobules were often separated by bands of fibrosis. In addition, in contrast with classical splenic hamartoma, cord capillary hemangioma was characterized by a predominance of CD8- CD31 + CD34 + cord capillaries with few sinuses. Myoid angioendothelioma was described as a solitary, well-circumscribed but unencapsulated mass of the spleen, which was characterized, in addition to small vessels lined by CD8 - CD31 + CD34 + endothelia as seen in cord capillary hemangioma, also by an abundance of large stromal cells with a myoid phenotype expressing vimentin, smooth muscle actin, and muscle specific actin, but not desmin. Histiocyte-rich hamartoma consists of rare cases of otherwise typical hamartomas, which were characterized by a predominance of cordal histiocytes associated with CD8- CD31+ CD34 + capillary vessels with a relative paucity of CD8 + splenic sinuses. ${ }^{17}$

The striking histologic and immunophenotypic differences between classical hamartoma and benign vascular tumors such as cord capillary hemangioma and myoid angioendothelioma raise the issue of whether the latter represents variants of hamartoma or rather morphologically and biologically distinct entities. In this study, we used immunohistology and histochemical methods to compare the vascular and stromal composition of classical hamartoma with cases of cord capillary hemangioma and myoid angioendothelioma. In addition, we assessed the clonality of these lesions by performing clonality analysis for X-chromosome inactivation at the human androgen receptor locus, an approach that can be used to establish clonality in specimens obtained from female patients.

\section{Materials and methods}

\section{Tissue Samples}

Formalin-fixed, paraffin-embedded tissue blocks of 17 splenectomy specimens were obtained from the case files of New York-Presbyterian Hospital-Weill Cornell Medical College (New York, NY, USA), Indiana University School of Medicine/Clarian Health Partners (Indianapolis, IN, USA), Massachusetts General Hospital (Boston, MA, USA), and University of Chicago (Chicago, IL, USA). These included seven cases of cord capillary hemangioma, six cases of classical splenic hamartoma, and four cases of myoid angioendothelioma. Four micron tissue sections were prepared from the paraffin blocks for routine morphologic evaluation, histochemistry, and immunohistochemistry. IRB approval was obtained at all institutions.

\section{Histochemistry}

Histochemical staining for reticulin and trichrome was performed using an automated stainer (Leica Microsystems, Bannockburn, IL, USA) according to the manufacturer's protocol with minor modifications.

\section{Immunohistochemistry}

Immunohistochemical studies were performed using a Bond-Max autostainer (Vision BioSystems, Hingham, MA, USA) using a polymer-defined peroxidase detection system after antigen retrieval with epitope retrieval solution 2 (Vision BioSystems). Monoclonal antibodies against the following antigens were used: CD8 (C8/144B; Dako North America, Carpinteria, CA, USA), collagen type IV (CIV 22; Dako), smooth muscle actin (1A4; Dako), low-affinity nerve growth factor receptor/LNGFR (ME20.4; Dako), CD31 (JC70A; Dako); CD34 (QBEND10; Biogenex Laboratories, San Ramon, CA, USA), D2-40 (D2-40; Covance, Berkeley, CA, USA), CD163 (10D6; Leica Microsystems/Novocastra; Newcastle-upon-Tyne, UK), and Ki-67 (7B11) (Zymed Laboratories, South San Francisco, CA, USA). In situ hybridization for 
Epstein Bar virus-encoded RNA (EBER) was performed using the Epstein Barr virus (EBV) probe ISH kit (Leica Microsystems/Novocastra) according to the manufacturer's protocol.

\section{Vascular Composition}

The vascular composition of each case was assessed by immunohistochemical staining for CD8, CD31, CD34, and D2-40. The density of positive vessels within the tumor was compared with the adjacent normal splenic tissue, and graded on a $0-2+$ scale (0, no increase; 1 , mildly increased; 2 , markedly increased). The evaluation was performed by using a $\times 40$ lens by averaging the findings of all lesional areas compared with the normal areas (a minimum of five $\times 40$ fields per section were analyzed).

\section{Stromal Composition}

The stromal composition of each case was evaluated by histochemical staining for reticulin (reactivity with all types of fibers) and trichrome (reactivity with collagen fibers), as well as by immunohistochemistry for the expression of type IV collagen, low-affinity nerve growth factor receptor, and smooth muscle actin. The degrees of reticulin and collagen fibrosis were compared with those of the adjacent normal splenic tissue and graded on a $0-2+$ scale $(0$, no increase; 1 , mildly increased; 2 , markedly increased relative to normal spleen). Immunohistochemical staining for low-affinity nerve growth factor receptor was performed to identify the adventitial reticular cells, and smooth muscle actin to identify myoid stromal cells within the lesional tissue. The positive cells for each marker were also determined on a $0-2+$ scale relative to adjacent normal spleen. CD163 immunostaining was used to enumerate histiocytes, whereas Ki-67 immunostaining was performed to assess the tumoral proliferation index. In situ hybridization for EBER was performed in all cases.

\section{HUMARA Assay}

The human androgen receptor X-chromosome inactivation assay (HUMARA) was performed on the specimens of 9 of 10 female patients. Four micron sections were prepared from the paraffin blocks. Laser-assisted microdissection of lesional and non-lesional spleen was performed using a PixCell II Laser Capture Microdissection system (Arcturus Engineering, Mountain View, CA, USA), as previously described. ${ }^{21} \mathrm{X}$-chromosome inactivation analysis was performed as previously described. ${ }^{22}$ Briefly, DNA samples were prepared from the lesional tissue and control normal spleen sections from the same patients. The sample was analyzed with and without digestion with HhaI restriction endonuclease. PCR was performed and the products were loaded onto polyacrylamide denaturing gels. Electrophoresis was performed and the resulting gel was analyzed using autoradiography. The samples were considered informative if the control sample displayed two alleles after PCR amplification without HhaI digestion. Non-random inactivation of the $\mathrm{X}$ chromosomes was defined as a complete or near complete absence of one or the other allele after HhaI digestion, indicating predominance of one X-linked human androgen receptor allele.

\section{Results}

\section{Clinical and Pathological Features}

The clinicopathological characteristics of the 17 cases are summarized in Table 1 . There were 10 women and 7 men ranging in age from 8 to 74 years (mean, 47 years). In six patients (cases 1, 2, 5, 7, 12, and 13), there was either an associated or past history of malignancy, including Hodgkin lymphoma, squamous cell carcinoma of the bladder, rhabdomyosarcoma, prostate carcinoma, and granulosa cell tumor of the ovary. One additional patient (case 16) has been previously diagnosed with sickle cell disease, whereas another (case 11) presented with iron deficiency anemia.

\section{Vascular Composition}

Of the 17 cases, 7 cases were classified as cord capillary hemangioma (Figure 1a). They showed a predominance of CD8 - CD31 + CD34 + cord capillaries with relatively few sinusoidal vessels (Figure $1 \mathrm{~b}$ and $\mathrm{c}$ ). Four of 17 cases were classified as myoid angioendothelioma (Figure 2a). These were composed of predominantly CD8- CD31+ CD34 + cord capillaries (Figure 2b and c) separated by an accumulation of plump stromal cells expressing smooth muscle actin (Figure 2d). Six of 17 cases were identified as classical splenic hamartoma. These were composed of a loose network of vascular channels and red pulp cordal histiocytes poorly delineated from the adjacent normal spleen (Figure 3a). The vessels were composed of predominantly CD8 + CD31 + CD34- splenic sinuses (Figure $3 \mathrm{~b}$ and c). Cord capillaries were present, but were few and widely separated. There were a variable number of lymphocytes, plasma cells, and histiocytes. However, no well-formed lymphoid follicles or peri-arteriolar lymphoid sheaths were seen. All cases lacked expression of the lymphatic marker D2-40. The uninvolved spleen showed a normal expression pattern for the various vascular markers, namely a predominance of CD8 + CD34sinusoidal vessels with a relative paucity of CD8CD34 + cord capillaries. CD31 highlighted both 
Table 1 Clinicopathological characteristics of cord capillary hemangioma, myoid angioendothelioma, and classical splenic hamartoma cases

No. Age Sex Subtype Retic Trich Coll LNGFR SMA CD34 CD31 CD8 D2-40 CD163 Ki-67 EBER HUMARA Other features

IV $\quad(\%)$

\begin{tabular}{|c|c|c|c|c|c|c|c|c|c|c|c|c|c|c|c|c|c|}
\hline 1 & 13 & $\mathrm{~F}$ & $\mathrm{CCH}$ & $1+$ & $1+$ & - & $2+$ & $1+$ & $2+$ & $1+$ & - & - & $2+$ & $<5$ & - & Clonal & H/O Hodgkin lymphoma \\
\hline 2 & 69 & $\mathrm{~F}$ & $\mathrm{CCH}$ & $1+$ & $0-1+$ & $0-1+$ & $0-1+$ & $0-1+$ & $2+$ & $2+$ & - & - & $1+$ & 5 & - & Non-clonal & $\mathrm{H} / \mathrm{O}$ bladder ca \\
\hline 3 & 62 & $\mathrm{~F}$ & $\mathrm{CCH}$ & $0-1+$ & - & $0-1+$ & $0-1+$ & $1+$ & $1+$ & $1+$ & - & - & $2+$ & $<5$ & - & Clonal & $+\mathrm{EMH}$ \\
\hline 4 & 31 & $\mathrm{~F}$ & $\mathrm{CCH}$ & $2+$ & $2+$ & - & $2+$ & $1+$ & $2+$ & $2+$ & - & - & $1+$ & $<5$ & - & Clonal & + Sclerosis \\
\hline 5 & 21 & $\mathrm{~F}$ & $\mathrm{CCH}$ & $2+$ & - & - & - & $0-1+$ & $1+$ & $1+$ & - & - & $1+$ & $<5$ & - & Non-clonal & H/O rhabdomyosarcoma \\
\hline 6 & 55 & M & $\mathrm{CCH}$ & $2+$ & $2+$ & - & $2+$ & $1+$ & $2+$ & $2+$ & - & - & $1+$ & $<5$ & - & ND & + Sclerosis \\
\hline 7 & 74 & M & $\mathrm{CCH}$ & $1+$ & - & - & - & - & $2+$ & $1+$ & - & - & $2+$ & $<5$ & - & ND & $\mathrm{H} / \mathrm{O}$ prostate ca; +EMH \\
\hline 8 & 59 & $\mathrm{~F}$ & MA & $2+$ & $2+$ & - & $1+$ & $2+$ & $2+$ & $1+$ & - & - & $1+$ & $<5$ & - & ND & \\
\hline 9 & 48 & M & MA & $2+$ & ND & $0-1+$ & $1+$ & $2+$ & $1+$ & $1+$ & - & - & $2+$ & 5 & - & ND & \\
\hline 10 & 66 & $\mathrm{~F}$ & MA & $2+$ & $1+$ & - & $2+$ & $2+$ & $2+$ & $2+$ & $0-1+$ & - & $1+$ & 5 & - & Non-clonal & +Bizarre stromal cells \\
\hline 11 & 24 & $\mathrm{~F}$ & MA & $2+$ & $2+$ & - & $2+$ & $2+$ & $1+$ & $1+$ & - & - & $1+$ & $<5$ & - & Non-clonal & H/O Iron-deficiency anemia \\
\hline 12 & 30 & $\mathrm{~F}$ & Classical & $1+$ & - & - & $0-1+$ & $1+$ & $1+$ & $1+$ & $2+$ & - & $1+$ & $<5$ & - & Non-clonal & H/O Hodgkin lymphoma \\
\hline 13 & 65 & $\mathrm{~F}$ & Classical & $1+$ & $1+$ & - & $0-1+$ & $1+$ & $1+$ & $1+$ & $2+$ & - & $1+$ & 5 & - & Non-clonal & H/O Granulosa cell tumor \\
\hline 14 & 62 & M & Classical & $0-1+$ & $0-1+$ & - & $0-1+$ & $1+$ & $1+$ & NS & $2+$ & - & $1+$ & $<5$ & - & ND & \\
\hline 15 & 41 & M & Classical & $1+$ & $1+$ & - & $2+$ & $1+$ & - & $1+$ & $1+$ & - & $1+$ & $<5$ & - & ND & \\
\hline 16 & 8 & M & Classical & $2+$ & $2+$ & - & $2+$ & $1+$ & - & $2+$ & $2+$ & - & $1+$ & $<5$ & - & ND & H/O Sickle cell disease \\
\hline 17 & 66 & M & Classical & $1+$ & $1+$ & - & $0-1+$ & $1+$ & $1+$ & $1+$ & $2+$ & - & $1+$ & $<5$ & - & ND & \\
\hline
\end{tabular}

Mean age 47 years (range, 8-74 years).

CCH, cord capillary hemangioma; MA, myoid angioendothelioma; Classical, classical hamartoma; Trich, trichrome; Coll IV, collagen IV; LNGFR, low affinity nerve growth factor receptor; SMA, smooth muscle actin; EBER, in situ hybridization for EBV-encoded RNA; HUMARA, human androgen receptor allele; ND, not done; H/O, history of; ca, carcinoma; EMH, extramedullary hematopoiesis.
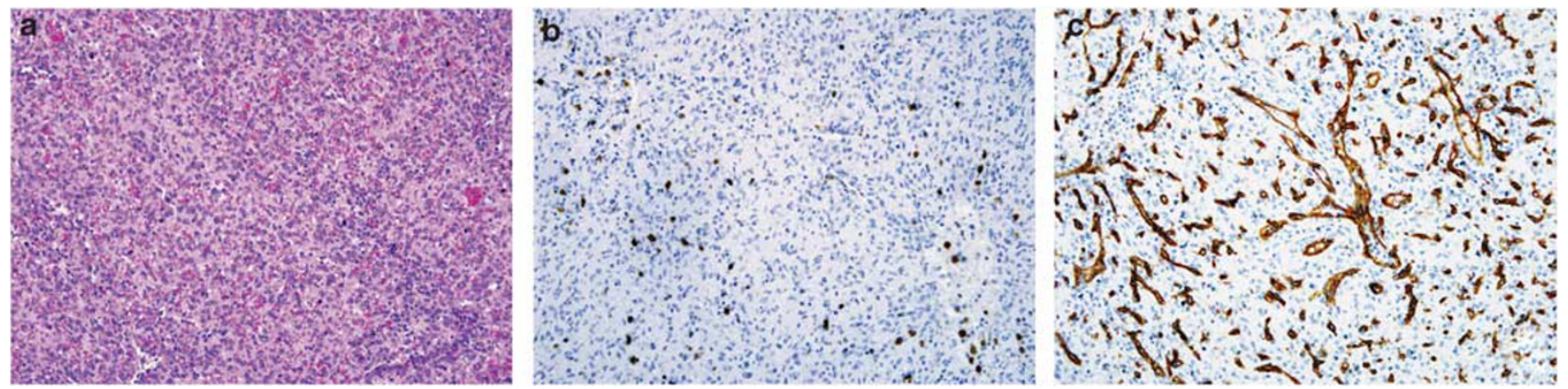

Figure 1 Morphologic and immunohistochemical characteristics of cord capillary hemangioma. (a) A case of cord capillary hemangioma (case 1) composed of a loose network of ill-defined vascular channels that are CD8- (b) and CD34+ (c), consistent with cord capillary phenotype.

types of vasculature both within the hamartomatous lesions and the normal splenic tissue.

\section{Stromal Composition}

Reticulin and trichrome histochemical stains were performed in all cases with the exception of case 9, in which only a reticulin stain was performed because of limited tissue availability. An increase in intralesional/perivascular reticulin content ( $1+$ or more) was seen in 15 of 17 cases, whereas 10 of 16 cases showed increased collagen content ( $1+$ or more). Seven of 11 cases exhibiting a nonclassical morphology showed an increased number of stromal cells expressing low-affinity nerve growth factor receptor, whereas two of six cases of classical hamartoma showed a significant increase for this marker. A minimal increase in subendothelial basement membrane collagen IV was seen in only three cases. Smooth muscle actin-positive cells were increased in 14 of 17 cases. The largest number of cells positive for smooth muscle actin, including plump myoid cells, was identified in the four cases of myoid angioendothelioma. An increased number of CD163-positive histiocytes was found in all cases. Significant sclerosis was identified in two cases (cases 4 and 6) of cord capillary hemangioma (Figure 4a and b), resembling the putatively pseudotumoral splenic lesion termed 'sclerosing angiomatoid nodular transformation' of the spleen originally described by Martel et al. ${ }^{23}$ Atypical, 'bizarre' stromal cells were seen in another case (case 10) of cord capillary hemangioma, a morphologic variation of splenic hamartoma previously described by Cheuk et al. ${ }^{24}$ Cases 3 and 7 showed the presence of extramedullary hematopoiesis in the uninvolved splenic tissue. All 17 cases had a low proliferation index as indicated by Ki-67 ( $\leq 5 \%$ in all cases). All 17 cases lacked evidence of EBV infection as indicated by their negativity for in situ hybridization for EBER.

\section{HUMARA Assay}

Non-random X-chromosome inactivation was informative in all nine evaluated cases; these included five cases of cord capillary hemangioma, two cases 

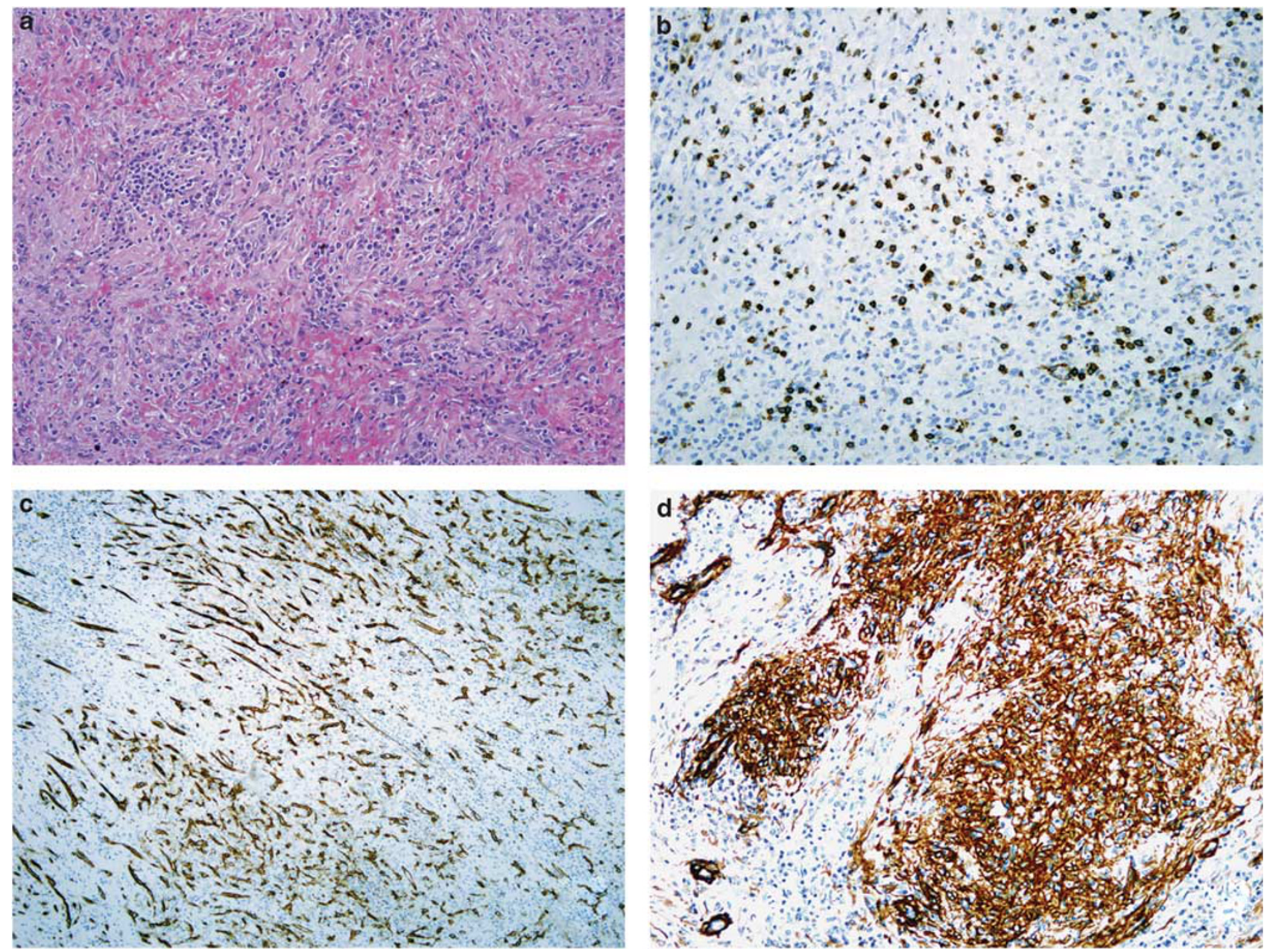

Figure 2 Morphologic and immunohistochemical characteristics of myoid angioendothelioma. (a) A case of myoid angioendothelioma (case 8) composed of CD8- (b) and CD34 + (c) vascular spaces, which are separated by large stromal cells expressing smooth muscle actin (d).
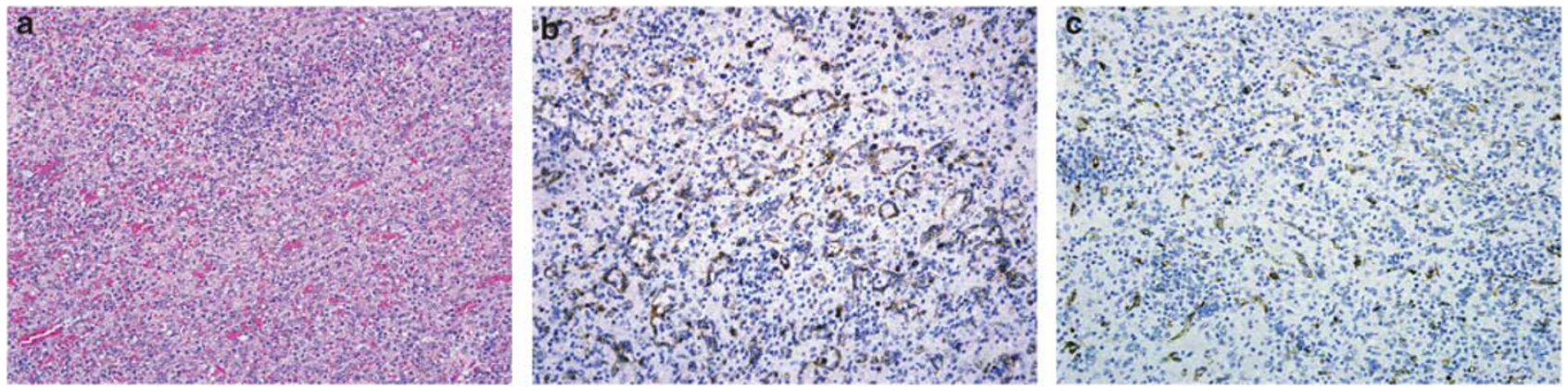

Figure 3 Morphologic and immunohistochemical characteristics of classical splenic hamartoma. (a) A case of classical hamartoma (case 14) is composed of sinus-like vasculature expressing CD8 (b), but negative for CD34 (c).

of myoid angioendothelioma, and two cases of classical splenic hamartoma. Of the five cases of cord capillary hemangioma, three cases (cases 1, 3, and 4) showed a non-random X-chromosome inactivation pattern, indicating clonality (Figure 5a). Both cases of myoid angioendothelioma showed a polyclonal pattern, as did both cases of classical splenic hamartoma (Figure 5b).

\section{Discussion}

Primary splenic tumors are relatively rare. Vascular lesions are the most common non-hematologic primary splenic tumors, most of which are benign vascular neoplasms such as hemangioma and lymphangioma. ${ }^{1,8}$ However, benign splenic vascular tumors are often difficult to distinguish from each 

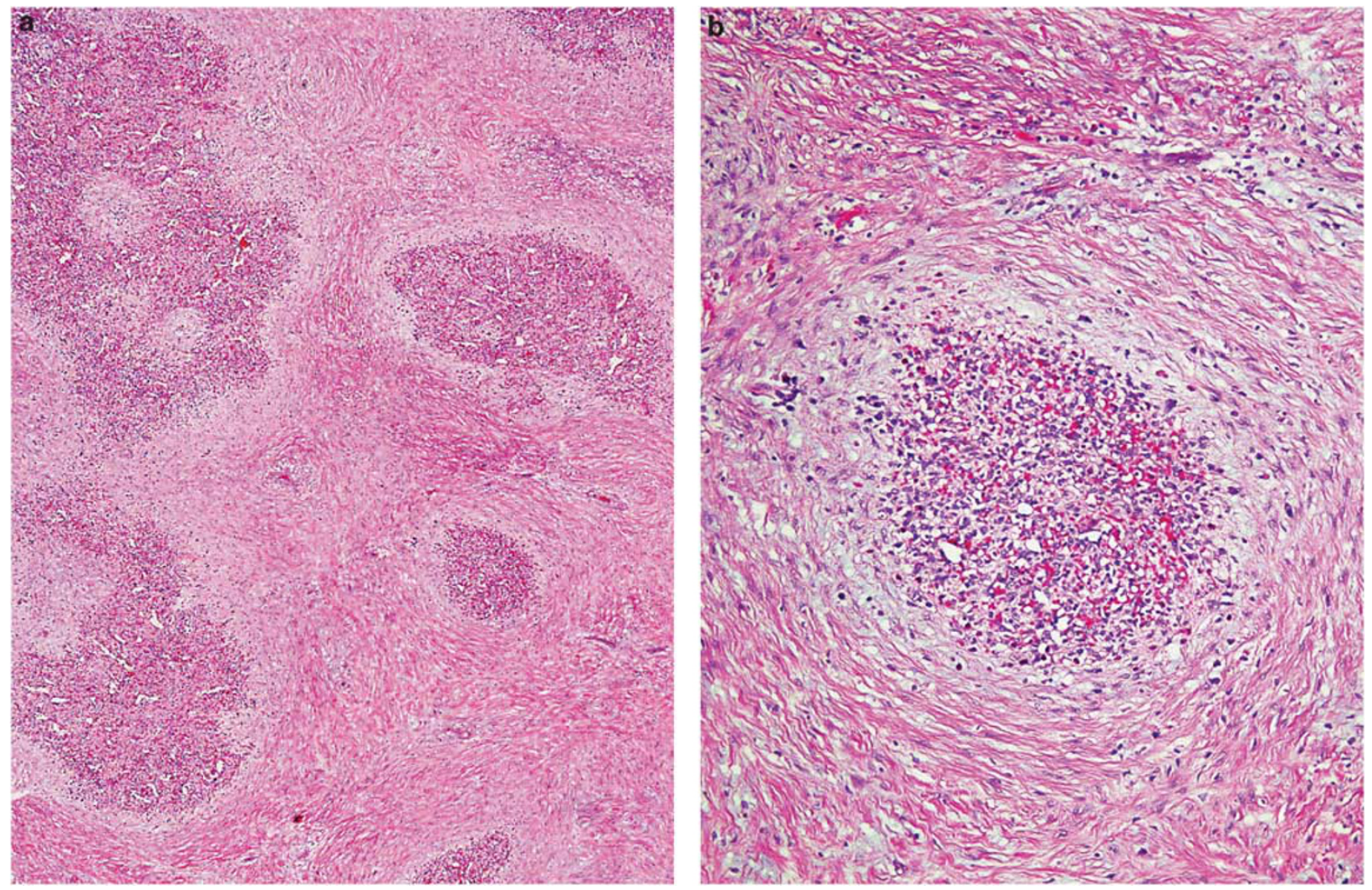

Figure 4 A case of cord capillary hemangioma with pronounced sclerosis (case 6). (a) On low magnification, the lesion shows a striking nodular appearance with vascular nodule surrounded by fibrosclerotic stroma. (b) The nodules are composed of vascular spaces lined by plump endothelial cells with extravasated erythrocytes. The morphologic features observed in two of our cases of cord capillary hemangioma overlap with those of ‘sclerosing angiomatoid nodular transformation' (SANT) of the spleen.
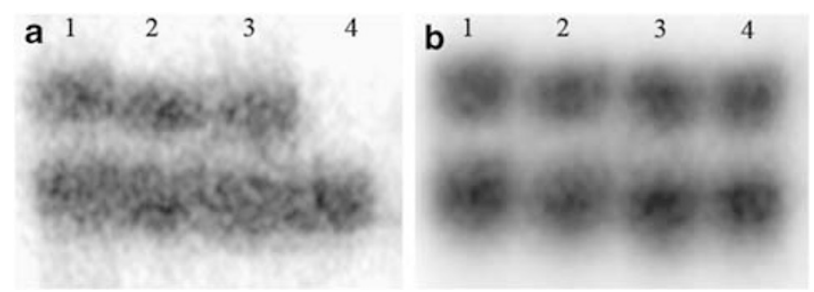

Figure 5 (a) HUMARA assay on a case of cord capillary hemangioma (case 1). Lanes 1 and 2, control tissue without and with HhaI digestion; lane 3, tumor tissue without digestion; lane 4, tumor tissue with digestion showing clonal pattern (nonrandom X-chromosome inactivation). (b) HUMARA assay on a case of classic hamartoma (case 14) showing polyclonal pattern. Lanes 1 and 2, control tissue without and with HhaI digestion; lane 3 , tumor tissue without digestion; lane 4, tumor tissue with digestion.

other and from pseudotumoral lesions such as splenic hamartoma and inflammatory pseudotumor, in part because of the low frequency and morphologic overlap between these lesions. Immunohistochemical studies are often of considerable help in the classification of these types of splenic lesions. ${ }^{8,25,26}$

Hemangiomas are the most common benign neoplasm of the spleen. Although the majority of the cases are of the cavernous type, capillary hemangioma is also occasionally seen. Although cavernous hemangioma is usually easily distinguished from splenic hamartoma by its gross and microscopic appearance, capillary hemangioma may be difficult to distinguish from splenic hamartoma both radiographically and histologically. ${ }^{8,25,26}$ However, there are important immunohistochemical differences between the two lesions. Although splenic hamartomas contain two types of vessels, namely CD8 + CD34- splenic sinuses, which form the bulk of the lesion vascularity, and relatively scarce CD8- CD34 + cord capillaries, hemangiomas are composed of a single type of blood vessel, that is capillaries lined by CD8- CD34 + endothelial cells. ${ }^{8,25,26}$ Littoral cell angioma, a rare benign vascular tumor of the spleen, can be easily distinguished from hamartoma in view of its typical morphological findings, that is a relatively monomorphic proliferation of sinus-like vascular channels displaying a characteristic CD8-, CD34-, CD68 + immunophenotype. ${ }^{27}$

Splenic pseudotumoral lesions included in the category 'hamartoma' are composed of red pulp elements arranged in variable proportions. Differences in the relative proportion of these elements, 
that is splenic sinuses and histiocytes, may account for the existence of variants such as histiocyte-rich hamartoma. ${ }^{17} \mathrm{~A}$ more complicated issue is the nature of cord capillary hemangioma. Whether or not cord capillary hemangioma is truly a benign vascular tumor or just a variant of hamartoma has never been resolved. ${ }^{17}$ In this study, we have confirmed that in spite of some overlapping features, cases of splenic hamartoma exhibiting classical morphology are different in terms of their vasculature and stromal composition from cases of cord capillary hemangioma. Specifically, cases of classical hamartoma show a predominance of CD8 + sinusoidal vasculature, whereas cases of cord capillary hemangioma and myoid angioendothelioma contain predominantly CD34 + cord capillaries and very little sinusoidal vasculature. Furthermore, of the five cases of cord capillary hemangioma evaluated by HUMARA assay, we showed clonality in three cases, supporting a true neoplastic origin for this lesion. Both cases of myoid angioendothelioma and both cases of classical hamartoma were polyclonal. The morphologic features of cord capillary hemangioma in our series, including the lack of atypia and the low proliferation index $(\leq 5 \%)$, are fully consistent with its categorization as a benign vascular neoplasm. Although two of five cases of cord capillary hemangioma showed a polyclonal pattern on HUMARA, several studies have shown that random X-chromosome inactivation is observed in only $50-60 \%$ of bona fide cancers. ${ }^{28-30}$ Persistence of biallelic bands after digestion by methylation-sensitive restriction enzyme in tumor samples may be attributed to several factors, including but not limited to incomplete digestion of DNA samples prepared from formalin-fixed, paraffin-embedded tissues, presence of X-chromosome aneuploidy, reactivation of inactive $\mathrm{X}$-chromosome-linked genes, and variable methylation patterns at the $\mathrm{CpG}$ sites of androgen receptor locus. ${ }^{31-33}$

Cord capillary hemangioma is a relative rare entity first described in 1993 by Krishnan et al ${ }^{18}$ in an abstract, whereas few other cases have also been subsequently reported. ${ }^{34,35}$ It was hypothesized by Krishnan and Frizzera ${ }^{17}$ that cord capillary hemangioma may represent a 'capillary-vessels-rich' variant of splenic hamartoma. Owing to the presence of both lobular architecture and significant sclerosis (as seen in two of our cord capillary hemangiomacases 4 and 6), a proportion of cord capillary hemangiomas show overlapping features with yet another putatively pseudotumoral splenic lesion, which has been termed 'sclerosing angiomatoid nodular transformation' of the spleen. Sclerosing angiomatoid nodular transformation, which was originally described by Martel et $a l^{23}$ in 2004, is thought to be a reactive response of the spleen secondary to vascular obstruction or to represent a terminal stage of inflammatory pseudotumors or organizing hematomas, although the authors conceded the possibility that sclerosing angiomatoid nodular transformation may represent a splenic hamartoma or possibly a benign vascular lesion, which has undergone sclerotic changes. Similar lesions have been described by others. ${ }^{36,37}$ In a more recent series of sclerosing angiomatoid nodular transformation cases, published by Diebold et al, ${ }^{38}$ one of the lesions was found adjacent to a splenic hemangioma. This suggests the possibility of a secondary response possibly to vascular obstruction and/or intratumoral thrombosis. In fact, sclerosing angiomatoid nodular transformation-like features can be commonly seen in the presence of thrombosed vessels, occurring both in reactive (eg thrombosed hemorrhoids) as well as neoplastic settings (eg surrounding metastases), as also suggested by Diebold et al. ${ }^{38}$ Sclerosing angiomatoid nodular transformation-like lesions have been described in spleens involved by carcinomas $^{39}$ and in the presence of splenic extramedullary hematopoiesis, particularly in cases with large extramedullary hematopoiesis nodules associated with sclerosis, a lesion also known as sclerosing extramedullary hematopoietic tumor. ${ }^{40}$ In a proportion of these cases, the presence of fibrotic stroma containing CD34-positive capillaries, but devoid of CD8-positive sinuses, result in a distinct nodularity and a close resemblance to sclerosing angiomatoid nodular transformation (Orazi, unpublished observation). Lastly, an overlap between sclerosing angiomatoid nodular transformation and splenic inflammatory pseudotumor has also been reported. This again points toward an obstructive vascular pathogenesis, particularly if one considers that a proportion of sclerotic splenic inflammatory pseudotumors, particularly those seen arising close to the splenic hilum, are of possible vascular derivation, ${ }^{8}$ the vessel having undergone thrombosis and subsequent sclerotic changes. A proportion of splenic inflammatory pseudotumors may represent a localized abnormal inflammatory response often rich in plasma cells, such as seen in cases of plasma cell granuloma of the lung. Similarly, sclerosing angiomatoid nodular transformation can also be quite heterogeneous; some sclerosing angiomatoid nodular transformation cases possess an abundance of plasma cells, particularly cases rich in the IgG4positive plasma cell subset. In addition, similarly to inflammatory pseudotumor, EBV participation has been documented in a few cases. ${ }^{41,42}$

In their 2003 review article, ${ }^{17}$ Krishnan and Frizzera stressed the concept that splenic sinuses and cord capillaries are both characteristic structures of the red pulp and that their respective relative predominance could result in classical hamartoma or cord capillary hemangioma, respectively. However, they also acknowledged that the striking histologic and immunohistochemical differences between classical hamartoma and cord capillary hemangioma may support the contention that they represent two distinct entities with an unclear biologic relationship. Our finding of clonality in 
cases of cord capillary hemangioma but not in classical splenic hamartoma or myoid angioendothelioma supports the notion that cord capillary hemangioma is indeed biologically distinct and represents a true vascular neoplasm. Thus, similar to cases included under the category 'inflammatory pseudotumor,' which include both polyclonal reactive lesions ('true inflammatory pseudotumor') as well as clonal proliferations (eg EBV-positive follicular dendritic cell-like pseudotumor), classical splenic hamartoma and cord capillary hemangioma, although sharing some morphologic features, are most likely biologically heterogeneous. Only a comprehensive analysis, including immunohistochemistry, cytogenetics, and molecular genetic studies permits a reproducible separation among these rare tumoral and pseudotumoral splenic lesions.

\section{Disclosure/conflict of interest}

The authors declare no conflict of interest.

\section{References}

1 Kraus MD, Fleming MD, Vonderheide RH. The spleen as a diagnostic specimen: a review of 10 years' experience at two tertiary care institutions. Cancer 2001;91:2001-2009.

2 Lam KY, Yip KH, Peh WC. Splenic vascular lesions: unusual features and a review of the literature. Aust $\mathrm{N}$ Z J Surg 1999;69:422-425.

3 Berge T. Splenoma. Acta Pathol Microbiol Scand 1965;63:333-339.

4 Falk S, Stutte HJ. Hamartomas of the spleen: a study of 20 biopsy cases. Histopathology 1989;14:603-612.

5 Ferguson ER, Sardi A, Beckman EN. Spontaneous rupture of splenic hamartoma. J La State Med Soc 1993;145:48-52.

6 Iakovidou J, Panayiotides J, Papacharalambous X, et al. Splenic hamartoma: a case report. Eur J Surg Oncol 1995;21:688-690.

7 Lee H, Maeda K. Hamartoma of the spleen. Arch Pathol Lab Med 2009;133:147-151.

8 Neiman RS, Orazi A. Splenic cysts, nonhematopoietic tumors, and tumorlike lesions. In: Livolsi VA (ed). Disorders of the Spleen, 2nd edn. W.B. Saunders: Philadelphia, 1999, pp 249-285.

9 Silverman ML, LiVolsi VA. Splenic hamartoma. Am J Clin Pathol 1978;70:224-229.

10 Singh K, Subbramaiah A, Choudhary SR, et al. Splenic hamartoma with portal hypertension: a case report. Trop Gastroenterol 1992;13:155-159.

11 Wirbel RJ, Uhlig U, Futterer KM. Splenic hamartoma with hematologic disorders. Am J Med Sci 1996;311:243-246.

12 Zissin R, Lishner M, Rathaus V. Unusual presentation of splenic hamartoma; computed tomography and ultrasonic findings. Clin Radiol 1992;45:410-411.

13 Garvin DF, King FM. Cysts and nonlymphomatous tumors of the spleen. Pathol Annu 1981;16:61-80.

14 Iozzo RV, Haas JE, Chard RL. Symptomatic splenic hemartoma: a report of two cases and review of the literature. Pediatrics 1980;66:261-265.
15 Hayes TC, Britton HA, Mewborne EB, et al. Symptomatic splenic hamartoma: case report and literature review. Pediatrics 1998;101:E10.

16 Steinberg JJ, Suhrland M, Valensi Q. The spleen in the spleen syndrome: the association of splenoma with hematopoietic and neoplastic disease-compendium of cases since 1864. J Surg Oncol 1991;47:193-202.

17 Krishnan J, Frizzera G. Two splenic lesions in need of clarification: hamartoma and inflammatory pseudotumor. Semin Diagn Pathol 2003;20:94-104.

18 Krishnan J, Danon A, Frizzera A. Use of anti-factor VIII-related antigen (F8) and QBEN10 (CD34) antibodies help classify the benign vascular lesions of the spleen. Mod Pathol 1993;6:94A.

19 Karim RZ, Ma-Wyatt J, Cox M, et al. Myoid angioendothelioma of the spleen. Int J Surg Pathol 2004;12: 51-56.

20 Kraus MD, Dehner LP. Benign vascular neoplasms of the spleen with myoid and angioendotheliomatous features. Histopathology 1999;35:328-336.

21 Cheng L, MacLennan GT, Zhang S, et al. Laser capture microdissection analysis reveals frequent allelic losses in papillary urothelial neoplasm of low malignant potential of the urinary bladder. Cancer 2004;101: 183-188.

22 Cheng L, Gu J, Eble JN, et al. Molecular genetic evidence for different clonal origin of components of human renal angiomyolipomas. Am J Surg Pathol 2001;25:1231-1236.

23 Martel M, Cheuk W, Lombardi L, et al. Sclerosing angiomatoid nodular transformation (SANT): report of 25 cases of a distinctive benign splenic lesion. Am J Surg Pathol 2004;28:1268-1279.

24 Cheuk W, Lee AK, Arora N, et al. Splenic hamartoma with bizarre stromal cells. Am J Surg Pathol 2005;29: 109-114.

25 Arber DA, Strickler JG, Chen YY, et al. Splenic vascular tumors: a histologic, immunophenotypic, and virologic study. Am J Surg Pathol 1997;21:827-835.

26 Zukerberg LR, Kaynor BL, Silverman ML, et al. Splenic hamartoma and capillary hemangioma are distinct entities: immunohistochemical analysis of CD8 expression by endothelial cells. Hum Pathol 1991;22: 1258-1261.

27 Falk S, Stutte HJ, Frizzera G. Littoral cell angioma. A novel splenic vascular lesion demonstrating histiocytic differentiation. Am J Surg Pathol 1991;15: 1023-1033.

28 Buller RE, Sood AK, Lallas T, et al. Association between nonrandom X-chromosome inactivation and BRCA1 mutation in germline DNA of patients with ovarian cancer. J Natl Cancer Inst 1999;91:339-346.

29 Enomoto T, Fujita M, Inoue $\mathrm{M}$, et al. Analysis of clonality by amplification of short tandem repeats. Carcinomas of the female reproductive tract. Diagn Mol Pathol 1994;3:292-297.

30 Guo Z, Thunberg U, Sallstrom J, et al. Clonality analysis of cervical cancer on microdissected archival materials by PCR-based X-chromosome inactivation approach. Int J Oncol 1998;12:1327-1332.

31 Gartler SM, Goldman MA. Reactivation of inactive X-linked genes. Dev Genet 1994;15:504-514.

32 Jang SJ, Mao L. Methylation patterns in human androgen receptor gene and clonality analysis. Cancer Res 2000;60:864-866.

33 Razin A, Cedar H. DNA methylation and genomic imprinting. Cell 1994;77:473-476. 
34 Miyamoto S, Takasugi K, Hata F, et al. A case of splenic cord capillary hemangioma. Jpn J Gastroenterol Surg 2009;42:1819-1825.

35 Kato M, Lubitz C, Finley D, et al. Splenic cord capillary hemangioma and anemia: resolution after splenectomy. Am J Hematol 2006;81:538-542.

36 El Demellawy D, Nasr A, Alowami S. Sclerosing angiomatoid nodular transformation of the spleen: case report. Pathol Res Pract 2009;205:289-293.

37 Koreishi AF, Saenz AJ, Fleming SE, et al. Sclerosing angiomatoid nodular transformation (SANT) of the spleen: a report of 3 cases. Int J Surg Pathol 2009;17:384-389.

38 Diebold J, Le Tourneau A, Marmey B, et al. Is sclerosing angiomatoid nodular transformation (SANT) of the splenic red pulp identical to inflammatory pseudotumour? Report of 16 cases. Histopathology 2008;53:299-310.
39 Fakan F, Michal M. Nodular transformation of splenic red pulp due to carcinomatous infiltration. A diagnostic pitfall. Histopathology 1994;25: 175-178.

40 Sukov WR, Remstein ED, Nascimento AG, et al. Sclerosing extramedullary hematopoietic tumor: emphasis on diagnosis by renal biopsy. Ann Diagn Pathol 2009;13:127-131.

41 Kashiwagi S, Kumasaka T, Bunsei N, et al. Detection of Epstein-Barr virus-encoded small RNA-expressed myofibroblasts and IgG4-producing plasma cells in sclerosing angiomatoid nodular transformation of the spleen. Virchows Arch 2008;453:275-282.

42 Nagai Y, Hayama N, Kishimoto T, et al. Predominance of IgG4+ plasma cells and CD68 positivity in sclerosing angiomatoid nodular transformation (SANT). Histopathology 2008;53:495-498. 